\title{
Genetic Information and Precision Medicine in Hearing Loss
}

\author{
Doo-Yi Oh (ii) · Byung Yoon Choi (i] \\ Department of Otorhinolaryngology, Seoul National University Bundang Hospital, Seongnam, Korea
}

Hearing loss (HL) is the most common sensory disorder, affecting at least one in 500 people in developed countries, and has the highest incidence rate of any congenital sensory organ disorder [1]. It occurs three times more often than Down syndrome or cystic fibrosis, which are especially common in western nations [2]. $\mathrm{HL}$ is caused by genetic and environmental factors that affect auditory pathways, such as congenital cytomegalovirus and ototoxicity caused by antibiotics [2]. Recently, with the decline in the prevalence of infectious diseases and the prevention of druginduced HL, the proportion of patients with genetic HL has correspondingly increased, and causative genetic variants have been found both for congenital mild or moderate HL and for severe or profound HL [3,4]. In addition, congenital recessive deafness gene variants are not uncommon in patients with sporadic HL, which is not evident at the beginning of birth but becomes apparent during childhood, adolescence, or adulthood, is not uncommon to report congenital recessive deafness gene variants [5].

The accelerated discovery of causative genetic variants has been strongly influenced by the Human Genome Project, which began in 1990 and ended in 2003, and next-generation sequencing (NGS), which has enabled tremendous changes in the landscape of the genetic biomarker market since its debut in 2004. The causes of HL include aging, exposure to ototoxic drugs, environmental insults, and genetic alterations, which are considered to account for $60 \%$ of HL [6]. Owing to developments in sequencing analysis methods, the range of hereditary HL is expanding to encompass congenital sensorineural HL, presbycusis, and noise-induced HL. On top of Sanger sequencing, the lineup of current tools of precision medicine in HL includes genetic screening kits and NGS technology-based methods. NGS technology can be divided into targeted exome sequencing (panel sequencing), exome sequencing (ES) and whole genome sequencing (WGS). Establishing an ethnicity-specific variant spectrum for HL enables simultaneous and preferential screening of the genetic variants for HL in a time- and cost-saving method. In Ko- rea, a diagnostic kit covering seven variants from three major genes (GJB2, SLC26A4, and mitochondria 12S rRNA) was developed based on microarray technology in 2009 [7], followed by the introduction of another diagnostic kit for 11 variants of five genes selected based on their prevalence in Korean HL patients in clinical settings [8]. Panel sequencing, which does not analyze the exome of the entire gene, but only analyzes the exome of genes known to be linked to deafness, has been the most popular method of HL screening since 2017. Compared to ES, panel sequencing is useful and has been established as the basic method of HL testing by clinicians, as it can analyze the sequence of genes at a much higher level with a low amount of DNA, as well as being time-saving, much less costly, and free from ethical problems derived from unwanted knowledge of genes unrelated to HL. Currently, the OtoSCOPE panel, which can analyze 152 HL genes responsible for nonsyndromic sensorineural HL, Pendred syndrome, and Usher syndrome, and the panel developed by Otogenetics Corporation, which can analyze 129 HL genes, are widely used around the world $[9,10]$. New HL genetic panels including all newly discovered HL genes have also been produced in Korea (e.g., Otoscan). However, if a gene has not been previously reported to cause HL, molecular diagnosis is not possible through panel sequencing due to its inherent limitations, and ES is necessary in such cases. ES is an important tool for identifying novel HL genes. The exome, which codes proteins, accounts for about $1.5 \%$ of the human genome, and the causative genetic variants for single-genetic diseases are mostly located in the exome region. By targeting only the protein-coding regions of the genome, ES reduces the time and expense compared toWGS. Numerous novel variants and HL genes in Sensorineural Hearing Loss have been identified by using ES; the first such gene was taperin (TPRN) [11], suggesting that ES is essential to find new HL genes. The number of new HL genes, discovered by either NGS alone or in conjunction with linkage analysis or homozygosity mapping, is expected to increase further in

Copyright (C) 2020 by Korean Society of Otorhinolaryngology-Head and Neck Surgery.

This is an open-access article distributed under the terms of the Creative Commons Attribution Non-Commercial License (https://creativecommons.org/licenses/by-nc/4.0) which permits unrestricted non-commercial use, distribution, and reproduction in any medium, provided the original work is properly cited. 
the future.

With its extreme etiologic heterogeneity and recent advances in these cutting-edge sequencing technologies, such as NGS and screening kits, the field of HL has been positioned as an ideal context for adoption of the strategies of precision medicine. Recently, a growing number of studies have reported surgical outcomes of cochlear implantation (CI) in association with causative genes for HL $[12,13]$. This approach has been particularly entered into the spotlight for the auditory rehabilitation of auditory neuropathy spectrum disorder (ANSD), which poses a significant dilemma in terms of appropriate auditory rehabilitation tools for both patients and otologists due to the uncertain outcomes of $\mathrm{CI}$ in these patients. Specifically, molecular genetic testing of the p.Glu831Lys variant of ATP1A3, previously known to cause cerebellar ataxia, areflexia, pes cavus, optic atrophy, and sensorineural hearing loss (CAPOS) syndrome, can serve as a biomarker that allows for the identification of a subset of postlingual-onset progressive ANSD subjects who can significantly benefit from CI, at least during short-term follow-up [14]. Without this genetic information, HL in patients with CAPOS syndrome would be considered "central" due to the accompanying deficits of the central nervous system, precluding the implementation of $\mathrm{CI}$ in these subjects. OTOF-related prelingual ANSD patients are also considered to have good prognosis for CI, if CI can be performed in a very timely fashion [15]. Considering the amount of residual hearing, it would be highly unlikely to perform early $\mathrm{CI}$ in those patients without the genetic information. In contrast, variants of DFNB59 and PCDH15 have been associated with a poor prognosis after CI [13]. Interestingly, a subset of patients with autoinflammatory inner ear diseases can show improvement of nonsyndromic HL if they carry an NLRP3 variant and receive anakinra treatment $[16,17]$.

Therefore, genetic information has become an important basis of auditory rehabilitation for HL patients beyond just identifying the cause of HL. Because the HL gene variant spectrum is very different in East Asian and Caucasian populations, it is not prudent to apply research results from other countries to the Korean population. In fact, many distinctive variants are exclusively found in East Asian populations or in the Korean population, warranting the establishment of ethnicity-specific variant spectra of HL.

Currently, many studies aiming to establish gene therapy for $\mathrm{HL}$ are at the animal testing stage. These gene therapies require a correct molecular genetic diagnosis. Successes in a subset of studies employing gene therapy, if not all, have shown improvements in cellular structure and vestibular function, as well as restoration of the neural response in the auditory cortex and recovery of behavioral responses. For example, mice with loss of Tmc1 function, a form of hereditary HL characterized by hair cell damage that causes moderate to severe HL with post-lingual onset, were found to have restored hearing, balance, and several secondary outcomes, suggesting that inner ear gene therapy for
Tmc1 mutations may be well-suited for further development and perhaps translation to the clinical setting [18]. Gene therapy will undoubtedly change the way that $\mathrm{HL}$ is treated over the next few decades.

Genetic information-based, precision medicine for the diagnosis and treatment of $\mathrm{HL}$ is emerging as a standard and crucial part of neuro-otology. Patients will receive personalized therapies that will improve both HL prevention and our current understanding of the treatment of HL.

\section{CONFLICT OF INTEREST}

No potential conflict of interest relevant to this article was reported.

\section{ORCID}

$\begin{array}{ll}\text { Doo-Yi Oh } & \text { https://orcid.org/0000-0003-0043-7790 } \\ \text { Byung Yoon Choi } & \text { https://orcid.org/0000-0001-5125-2118 }\end{array}$

\section{AUTHOR CONTRIBUTIONS}

Conceptualization: BYC. Data curation \& Formal analysis: DYO. Funding acquisition: BYC. Methodology: DYO. Project administration: BYC. Visualization: BYC. Writing-original draft: DYO. Writing-review \& editing: BYC.

\section{REFERENCES}

1. Morton CC, NanceWE. Newborn hearing screening: a silent revolution. N Engl J Med. 2006 May;354(20):2151-64.

2. Smith RJ, Bale JF Jr, White KR. Sensorineural hearing loss in children. Lancet. 2005 Mar;365(9462):879-90.

3. Kim NK, Kim AR, Park KT, Kim SY, Kim MY, Nam JY, et al. Wholeexome sequencing reveals diverse modes of inheritance in sporadic mild to moderate sensorineural hearing loss in a pediatric population. Genet Med. 2015 Nov;17(11):901-11.

4. Kim BJ, Oh DY, Han JH, Oh J, Kim MY, Park HR, et al. Significant Mendelian genetic contribution to pediatric mild-to-moderate hearing loss and its comprehensive diagnostic approach. Genet Med. 2020 Jun;22(6):1119-28.

5. Yu Y, Yang Y, Lu J, Jin Y, Yang Y, Hong E, et al.Two compound heterozygous were identified in SLC26A4 gene in two Chinese families with enlarged vestibular aqueduct. Clin Exp Otorhinolaryngol. 2019 Feb;12(1):50-7.

6. Van Camp G, Smith RJ. Hereditary hearing loss homepage [Internet]. 2020 [cited 2020 Oct 19]. Available from: https://hereditaryhearingloss.org.

7. Choi SY, Kim YE,Ahn DB, Kim TH, Choi JH, Lee HR, et al. Construction of a DNA chip for screening of genetic hearing loss. Clin Exp Otorhinolaryngol. 2009 Mar;2(1):44-7.

8. Han KH, Kim AR, Kim MY,Ahn S, Oh SH, Song JH, et al. Establish- 
ment of a flexible real-time polymerase chain reaction-based platform for detecting prevalent deafness mutations associated with variable degree of sensorineural hearing loss in Koreans. PLoS One. 2016 Sep;11(9):e0161756.

9. Shearer AE, DeLuca AP, Hildebrand MS, Taylor KR, Gurrola J 2nd, Scherer S, et al. Comprehensive genetic testing for hereditary hearing loss using massively parallel sequencing. Proc Natl Acad Sci USA. 2010 Dec;107(49):21104-9.

10. Tang W, Qian D, Ahmad S, Mattox D, Todd NW, Han H, et al. A lowcost exon capture method suitable for large-scale screening of genetic deafness by the massively-parallel sequencing approach. Genet Test Mol Biomarkers. 2012 Jun;16(6):536-42.

11. Rehman AU, Morell RJ, Belyantseva IA, Khan SY, Boger ET, Shahzad $\mathrm{M}$, et al. Targeted capture and next-generation sequencing identifies C9orf75, encoding taperin, as the mutated gene in nonsyndromic deafness DFNB79. Am J Hum Genet. 2010 Mar;86(3):378-88.

12. Nishio SY, Usami SI. Outcomes of cochlear implantation for the patients with specific genetic etiologies: a systematic literature review. Acta Otolaryngol. 2017 Jul;137(7):730-42.

13. Wu CC, Lin YH, Liu TC, Lin KN, Yang WS, Hsu CJ, et al. Identifying children with poor cochlear implantation outcomes using massively parallel sequencing. Medicine (Baltimore). 2015 Jul;94(27):e1073.

14. Han KH, Oh DY, Lee S, Lee C, Han JH, Kim MY, et al. ATP1A3 mutations can cause progressive auditory neuropathy: a new gene of auditory synaptopathy. Sci Rep. 2017 Nov;7(1):16504.

15. Kim BJ, Jang JH, Han JH, Park HR, Oh DY, Lee S, et al. Mutational and phenotypic spectrum of OTOF-related auditory neuropathy in Koreans: eliciting reciprocal interaction between bench and clinics. J Transl Med. 2018 Nov;16(1):330.

16. Nakanishi H, Kawashima Y, Kurima K, Chae JJ, Ross AM, Pinto-Patarroyo G, et al. NLRP3 mutation and cochlear autoinflammation cause syndromic and nonsyndromic hearing loss DFNA34 responsive to anakinra therapy. Proc Natl Acad Sci U SA. 2017 Sep;114(37): E7766-75.

17. Kim BJ, Kim YH, Lee S, Han JH, Lee SY, Seong J, et al. Otological aspects of NLRP3-related autoinflammatory disorder focusing on the responsiveness to anakinra. Rheumatology (Oxford). 2020 Oct 6 [Epub]. https://doi.org/10.1093/rheumatology/keaa511.

18. Nist-Lund CA, Pan B, Patterson A, Asai Y, Chen T, ZhouW, et al. Improved TMC1 gene therapy restores hearing and balance in mice with genetic inner ear disorders. Nat Commun. 2019;10(1):236. 